\title{
Association of Serum Total Iron-Binding Capacity and Its Changes Over Time with Nutritional and Clinical Outcomes in Hemodialysis Patients
}

\author{
Rachelle Bross $^{a, b}$ Jennifer Zitterkoph ${ }^{b}$ Juhi Pithia ${ }^{c}$ Deborah Benner ${ }^{d}$ \\ Mehdi Rambod $^{a}$ Csaba P. Kovesdy ${ }^{\mathrm{e}}$ Joel D. Kopple ${ }^{\mathrm{a}}$ Kamyar Kalantar-Zadeh $^{\mathrm{a}}$ \\ ${ }^{a}$ Harold Simmons Center for Kidney Disease Research and Epidemiology, and b Division of Bionutrition at \\ General Clinical Research Center, Los Angeles Biomedical Research Institute at Harbor-UCLA Medical Center, \\ Torrance, Calif., 'DaVita Wild West, Downey, Calif., ${ }^{\text {d} D a V i t a ~ N u t r i t i o n ~ S e r v i c e s, ~ I r v i n e, ~ C a l i f ., ~ a n d ~ e S a l e m ~ V A ~ M e d i c a l ~}$ \\ Center, Salem, Va., USA
}

\section{Key Words}

Transferrin - Total iron-binding capacity $\cdot$ Chronic kidney disease $\cdot$ Hemodialysis $\cdot$ Protein-energy wasting

\begin{abstract}
Serum transferrin, estimated by total iron-binding capacity (TIBC), may be a marker of protein-energy wasting (PEW) in maintenance hemodialysis (MHD) patients. We hypothesized that low TIBC or its fall over time is associated with poor clinical outcomes. In 807 MHD patients in a prospective 5year cohort, associations of TIBC and its changes over time with outcomes were examined after adjustment for casemix and markers of iron stores and malnutrition-inflammation including serum interleukin-6, iron and ferritin. Patients with serum TIBC $\geq 250 \mathrm{mg} / \mathrm{dl}$ had higher body mass index, triceps and biceps skinfolds and mid-arm muscle circumference and higher serum levels of iron but lower ferritin and inflammatory markers. Some SF-36 quality of life (QoL) components were worse in the lowest and/or highest TIBC groups. Mortality was incrementally higher in lower TIBC levels ( $p$-trend $<0.001$ ). Adjusted death hazard ratio was 1.75 (95\% Cl: $1.00-3.05, p=0.05$ ) for TIBC $<150$ compared to TIBC of $200-250 \mathrm{mg} / \mathrm{dl}$. A fall in TIBC $>20 \mathrm{mg} / \mathrm{dl}$ over 6 months was associated with a death hazard ratio of 1.57 (95\% Cl: $1.04-$
\end{abstract}

2.36, $p=0.03$ ) compared to the stable TIBC group. Hence, low baseline serum TIBC is associated with iron deficiency, PEW, inflammation, poor QoL and mortality, and its decline over time is independently associated with increased death risk.

Copyright $\odot 2009$ S. Karger AG, Basel

\section{Introduction}

Many individuals with advanced chronic kidney disease (CKD) including those undergoing maintenance hemodialysis (MHD) treatment suffer from protein-energy wasting (PEW), also referred to as uremic malnutrition $[1,2]$. PEW and inflammation, which often occur together in CKD and which are hence referred to collectively as the malnutrition-inflammation complex (or cachexia) syndrome (MICS), are associated with poor quality of life and increased morbidity and mortality [3-6]. Examining the relative contribution of the various components of the MICS to poor outcomes may lead to discovering modifiable mechanisms that underlie poor CKD survival. However, it is not known what nutritional or inflammatory markers are more appropriate or robust for studying the MICS-mortality association.

\section{KARGER}

Fax +4161306 1234 E-Mail karger@karger.ch www.karger.com (c) 2009 S. Karger AG, Basel

0250-8095/09/0296-0571\$26.00/0

Accessible online at:

www.karger.com/ajn
Kamyar Kalantar-Zadeh, MD, MPH, PhD

Harold Simmons Center for Kidney Disease Research and Epidemiology

Los Angeles Biomedical Research Institute at Harbor-UCLA Medical Center

1124 West Carson Street, C1-Annex, Torrance, CA 90502 (USA)

Tel. +1 310222 3891, Fax +1 310782 1837, E-Mail kamkal@ucla.edu 
The International Society of Renal Nutrition and Metabolism (ISRNM) Expert Panel has recently suggested a series of criteria to assess nutritional status and inflammation in CKD [2]. Among the biochemical markers, a low level of serum transferrin, which is a traditional marker of nutritional status and which can be measured directly via conventional radioimmunoassays (RIA), is suggested as a potential indicator of PEW [2]. In CKD patients, however, serum transferrin concentration is usually assessed indirectly by measuring serum total iron-binding capacity (TIBC) [7-9]. There is a high statistical correlation between RIA-measured serum transferrin and iron-binding-based measured TIBC with a correlation coefficient $\mathrm{R}^{2}$ of 0.95 or greater [7].

Transferrin is a $90-\mathrm{kDa}$ beta-globulin that binds and transports iron in the plasma [10]. The liver is the primary site of synthesis. Low values are found in many disease states including infection, malignancy, hepatocellular disease, and nephrotic syndrome [9]. In the general population, increased serum transferrin values occur in iron deficiency, pregnancy and other high estrogen and progesterone states including administration of oral contraceptives [11]. However, in CKD patients, iron deficiency may be paradoxically associated with lower TIBC values $[7,12]$. TIBC is indeed the denominator of the iron saturation ratio', i.e. iron divided by TIBC [12]. Despite being suggested as a marker of PEW by the ISRNM consensus committee [2], it is not clear whether the TIBC calculated transferrin is an independent predictor of mortality and other outcomes in CKD patients. Moreover, the association between TIBC and other clinical outcomes such as health-related quality of life (HR-QoL) has not yet been studied.

Given the fact that TIBC is measured monthly in virtually all 400,000 dialysis patients in the United States to calculate the iron saturation ratio, we sought to examine the utility of serum TIBC and its changes over time in assessing the nutritional status and in predicting HRQoL and mortality after controlling for iron markers and surrogates of nutritional status and inflammation including circulating levels of pro-inflammatory cytokines. We analyzed the data from a well-studied National Institute of Health (NIH) sponsored cohort of 807 MHD patients who were followed for up to 5 years and in whom repeated nutritional and inflammatory measures including cytokines, body composition and HRQoL were assessed. We hypothesized that TIBC is an independent outcome predictor in MHD patients and that its changes over time have a bearing on relevant clinical outcomes.

\section{Methods}

\section{Subjects and Setting}

We studied MHD patients who were participating in the Nutritional and Inflammatory Evaluation in Dialysis (NIED) Study [13]. The original patient cohort was derived from a pool of approximately 1,300 MHD outpatients in eight DaVita, Inc., chronic dialysis facilities in the South Bay Los Angeles area (see NIED Study website at www.NIEDStudy.org for more details). Inclusion criteria were outpatients who had been undergoing MHD for at least 8 weeks, were 18 years or older and who signed a local Institutional Review Board approved consent form. Patients with an anticipated life expectancy of less than 6 months (for example, due to a metastatic malignancy or advanced HIV/AIDS disease) were excluded. From October 1, 2001, through December 31, 2006, 893 MHD patients from eight DaVita dialysis facilities in the Los Angeles South Bay area signed the informed consent form and underwent the periodic evaluations of the NIED Study. For these analyses, data including baseline serum TIBC, to reflect serum transferrin, were available in $807 \mathrm{MHD}$ patients.

The medical chart of each MHD patient was thoroughly reviewed by a collaborating physician, and data pertaining to underlying kidney disease, cardiovascular history and other comorbid conditions were extracted. A modified version of the Charlson comorbidity index, i.e. without the age and kidney disease components, was used to assess the severity of comorbidities [14, 15]. The 807 MHD patients were followed for up to 63 months, i.e. until December 31, 2006.

\section{Health-Related Quality of Life Scores}

The SF36, a short form HR-QoL scoring system with 36 items, which includes eight independent scales, is a well-documented, self-administered questionnaire and has been widely used and validated in MHD patients $[6,16]$. The eight scales of SF36 are summarized into two dimensions: 'Physical health' and 'Mental health'.

\section{Anthropometric Measures}

Body weight assessment and anthropometric measurements were performed while patients were undergoing a hemodialysis treatment or within 5-20 min after termination of the treatment. Biceps skinfold and triceps skinfold thicknesses were measured with a conventional skinfold caliper using standard techniques as previously described $[17,18]$.

\section{Near Infrared Interactance}

To estimate the percentage of body fat and fat-free body mass, near infrared (NIR) interactance technology was utilized at the same time as the anthropometric measurements $[19,20]$. A commercial near-infrared interactance sensor with a coefficient of variation of $0.5 \%$ for total body fat measurement (portable Futrex $6100^{\circledR}$, Gaithersburg, Md., USA, www.futrex.com) was used. NIR measurements were performed by placing a Futrex ${ }^{\circledR}$ sensor on the nonaccess upper arm for several seconds, and entering the required data (date of birth, gender, weight and height) of each patient. NIR measurements of body fat have been shown to correlate significantly with other nutritional measures in MHD patients [20]. 


\section{Laboratory Tests}

Predialysis blood samples and postdialysis serum urea nitrogen were obtained on a mid-week day, which coincided chronologically with the drawing of quarterly blood tests in the DaVita facilities. The single-pool Kt/V was used to represent the weekly dialysis dose. All routine laboratory measurements were performed by DaVita ${ }^{\circledR}$ Laboratories (Deland, Fla., USA) using automated methods. TIBC was measured using the summation of a measured serum total iron and a measured unbound iron-binding capacity (UIBC), which is measured spectrophotometrically. The test principle uses a known concentration of iron to saturate the available binding sites on the transferrin [21]. A final reaction occurs using excess unbound divalent iron with a FerroZine chromogen to form a magenta complex that is measured.

Serum high sensitivity C-reactive protein (CRP) was measured by a turbidometric immunoassay in which a serum sample is mixed with latex beads coated with anti-human CRP antibodies forming an insoluble aggregate (manufacturer: WPCI, Osaka, Japan, unit: $\mathrm{mg} / \mathrm{l}$, normal range: $<3.0 \mathrm{mg} / \mathrm{l})$ [22, 23]. Interleukin 6 (IL-6) and tumor necrosis factor alpha (TNF- $\alpha$ ) were measured with immunoassay kits based on a solid-phase sandwich ELISA using recombinant human IL- 6 and TNF- $\alpha$ (manufacturer: R\&D Systems, Minneapolis, Minn., USA; units: $\mathrm{pg} / \mathrm{ml}$; normal range: IL- $6:<9.9 \mathrm{pg} / \mathrm{ml}$, TNF- $\alpha:<4.7 \mathrm{pg} / \mathrm{ml})[24,25]$. CRP and the cytokines were measured in the General Clinical Research Center Laboratories of Harbor-UCLA Medical Center. Plasma total homocysteine concentrations were determined by high-performance liquid chromatography in the Harbor-UCLA Clinical Laboratories. Serum transthyretin (prealbumin) was measured using immunoprecipitin analysis [26].

\section{Statistical Methods}

Pearson's correlation coefficient ( $r$ ) was used for analyses of linear associations. Simple linear regression and $\chi^{2}$ test for trend were used to examine trends of continuous and dichotomous variables, respectively, across the four groups of TIBC. Multivariate regression analyses and analysis of covariance were performed to obtain adjusted $\mathrm{p}$ values controlled for case-mix and other covariates. A restricted cubic splines graph was utilized as an exploratory data analysis (EDA) strategy to illustrate systematic relations between serum TIBC and mortality. This method also served to examine the non-linear associations as continuous mortality predictors as an alternative to inappropriate linearity assumptions [27]. Thereafter, to calculate the relative risks of death, hazard ratios (HR) were obtained using Cox proportional hazard models after controlling for the relevant covariates. Plots of $\log [-\log$ (survival rate)] against log (survival time) were performed to establish the validity of the proportionality assumption. Kaplan-Meier analyses were utilized to assess the differences in surviving proportions between categories of TIBC change. Case-mix and comorbidity covariates included gender, age, race and ethnicity (Hispanics, African-Americans, Asians and others), diabetes mellitus, the modified Charlson comorbidity scale, dialysis vintage (number of months on MHD treatment), and serum iron; and laboratory measures of the MICS in fully adjusted Cox models included serum CRP, IL-6, and albumin concentrations. To mitigate the regression to the mean phenomenon, baseline serum TIBC was included as a covariate in all Cox proportional hazard models utilized to assess the death HRs of TIBC change. Fiducial limits are given as mean \pm SD or median and

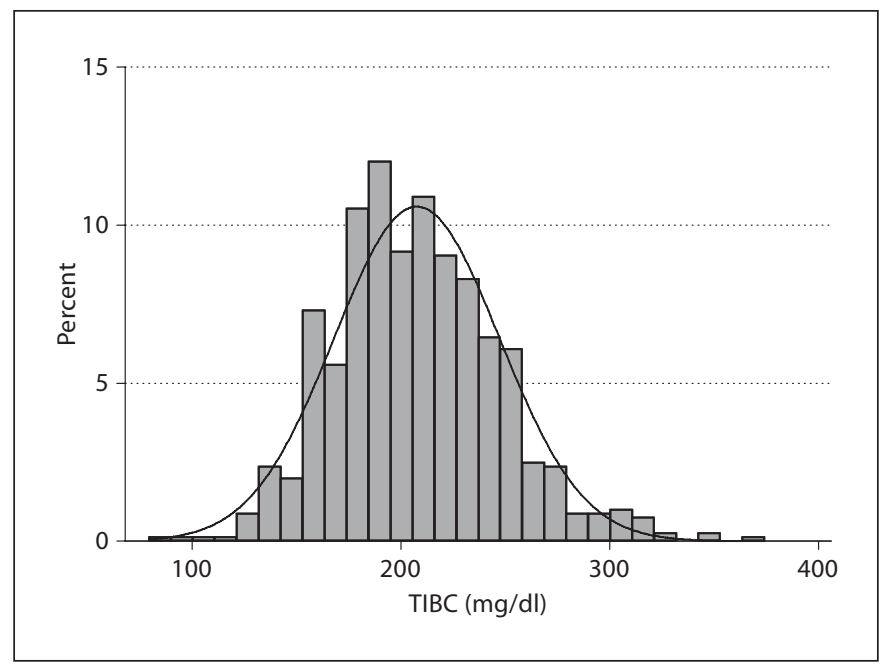

Fig. 1. Distribution of the baseline serum TIBC in 807 maintenance hemodialysis patients.

interquartile range, when appropriate; risk ratios include 95\% CI levels. $\mathrm{p}<0.05$ or a $95 \%$ CI that did not span 1.0 was considered to be statistically significant. A p value between 0.05 and 0.20 is also listed with 2 decimals to identify potential type II errors. Descriptive and multivariate statistics were carried out with the statistical software 'Stata version 10.0' (Stata Corporation, College Station, Tex., USA).

\section{Results}

\section{General and Laboratory Characteristics}

Baseline demographic, clinical, and laboratory values in the 807 MHD patients under study are shown in table 1. Patients' mean age $( \pm S D)$ was $53.6 \pm 14.8$ years; $47 \%$ of patients $(n=379)$ were women, $50 \%(n=406)$ were Hispanic and $32 \%(n=257)$ were African-American. The mean dialysis vintage was $31 \pm 34$ months (median: 19.2, inter-quartile range: 7-46 months). As depicted in figure 1, the average baseline serum TIBC in the 807 MHD patients was $208 \pm 40 \mathrm{mg} / \mathrm{dl}$ (median: 205, minimum: 79, maximum: 374, inter-quartile range: 181-232 mg/ dl).

We selected four a priori categories of serum TIBC levels with $50-\mathrm{mg} / \mathrm{dl}$ increments based on the practical clinical utility of the cutoff levels and as suggested in the malnutrition-inflammation score (MIS) by Kalantar-Zadeh et al. [4] $<150 \mathrm{mg} / \mathrm{dl}(\mathrm{n}=39,5 \%), 150$ to $<200 \mathrm{mg} / \mathrm{dl}(\mathrm{n}=330$, $41 \%), 200$ to $<250 \mathrm{mg} / \mathrm{dl}(\mathrm{n}=326,40 \%)$ and $\geq 250 \mathrm{mg} / \mathrm{dl}$ ( $\mathrm{n}=112,14 \%)$. Table 1 shows the relevant demographic, 
Table 1. Baseline demographic, clinical, and laboratory values in total and according to the four a priori selected groups of TIBC in 807 maintenance hemodialysis patients

\begin{tabular}{|c|c|c|c|c|c|c|}
\hline \multirow[t]{2}{*}{ Variable } & \multicolumn{6}{|l|}{ TIBC, mg/dl } \\
\hline & $\begin{array}{l}\text { total } \\
(\mathrm{n}=807)\end{array}$ & $\begin{array}{l}<150 \\
(\mathrm{n}=39)\end{array}$ & $\begin{array}{l}150 \text { to }<200 \\
(\mathrm{n}=330)\end{array}$ & $\begin{array}{l}200 \text { to }<250 \\
(n=326)\end{array}$ & $\begin{array}{l}\geq 250 \\
(\mathrm{n}=112)\end{array}$ & $\begin{array}{l}\mathrm{p} \text { for } \\
\text { trend }\end{array}$ \\
\hline \multicolumn{7}{|l|}{ Demographic } \\
\hline Age, years & $53.7 \pm 14.7$ & $53.7 \pm 16.4$ & $54.8 \pm 14.7$ & $53.4 \pm 14.3$ & $51.5 \pm 14.8$ & 0.06 \\
\hline Women, \% & 47 & 51 & 51 & 45 & 38 & 0.01 \\
\hline Marital status: \% married & 47 & 35 & 41 & 53 & 51 & 0.007 \\
\hline Race: \% African-American & 32 & 41 & 34 & 31 & 25 & 0.03 \\
\hline Ethnicity: \% Hispanic & 50 & 56 & 51 & 48 & 53 & 0.71 \\
\hline Primary insurance: \% Medicare & 52 & 53 & 53 & 51 & 54 & 0.91 \\
\hline Diabetes mellitus, \% & 56 & 49 & 59 & 53 & 58 & 0.79 \\
\hline Charlson comorbidity score & $1.9 \pm 1.6$ & $1.6 \pm 1.5$ & $2.0 \pm 1.6$ & $1.8 \pm 1.7$ & $1.9 \pm 1.6$ & 0.77 \\
\hline Mortality, \% & 30 & 51 & 33 & 27 & 20 & $<0.001$ \\
\hline \multicolumn{7}{|l|}{ Body composition } \\
\hline Body mass index & $26.5 \pm 6.1$ & $24.6 \pm 5.3$ & $26.2 \pm 6.1$ & $26.8 \pm 6.1$ & $27.2 \pm 6.5$ & 0.03 \\
\hline Triceps skinfold, mm & $17.6 \pm 10.0$ & $14.0 \pm 9.0$ & $17.6 \pm 9.8$ & $17.4 \pm 10.1$ & $19.7 \pm 10.4$ & 0.03 \\
\hline Biceps skinfold, mm & $9.9 \pm 7.9$ & $8.6 \pm 7.6$ & $9.6 \pm 7.4$ & $10.0 \pm 7.9$ & $11.1 \pm 9.4$ & 0.06 \\
\hline Mid-arm muscle circumference, $\mathrm{cm}$ & $25.9 \pm 4.4$ & $25.0 \pm 3.8$ & $25.7 \pm 4.7$ & $26.3 \pm 3.9$ & $26.2 \pm 4.9$ & 0.08 \\
\hline Near infrared measured body fat, \% & $26.6 \pm 10.8$ & $24.6 \pm 10.8$ & $26.6 \pm 10.9$ & $26.6 \pm 10.8$ & $27.0 \pm 10.9$ & 0.48 \\
\hline \multicolumn{7}{|l|}{ Hemodialysis treatment measures } \\
\hline Dialysis vintage, months & $31.1 \pm 33.7$ & $51.0 \pm 36.7$ & $35.6 \pm 33.6$ & $27.8 \pm 34.2$ & $20.2 \pm 26.3$ & $<0.001$ \\
\hline Dialysis dose, Kt/V single pool & $1.61 \pm 0.31$ & $1.59 \pm 0.32$ & $1.61 \pm 0.30$ & $1.60 \pm 0.31$ & $1.63 \pm 0.32$ & 0.69 \\
\hline $\mathrm{nPCR}, \mathrm{g} \cdot \mathrm{kg}^{-1} \cdot \mathrm{day}^{-1}$ & $1.06 \pm 0.24$ & $0.98 \pm 0.22$ & $1.05 \pm 0.23$ & $1.09 \pm 0.24$ & $1.07 \pm 0.26$ & 0.03 \\
\hline Erythropoietin dose, 1,000 U/week & $14.5 \pm 12.6$ & $22.5 \pm 18.5$ & $14.7 \pm 12.7$ & $13.5 \pm 11.6$ & $14.4 \pm 12.2$ & 0.026 \\
\hline \multicolumn{7}{|l|}{ Biochemical measurements } \\
\hline Albumin, g/dl & $3.88 \pm 0.38$ & $3.55 \pm 0.48$ & $3.81 \pm 0.39$ & $3.98 \pm 0.33$ & $3.97 \pm 0.34$ & $<0.001$ \\
\hline Transthyretin (prealbumin), mg/dl & $28.1 \pm 9.7$ & $20.9 \pm 8.0$ & $27.4 \pm 8.8$ & $29.6 \pm 10.3$ & $27.8 \pm 9.4$ & 0.001 \\
\hline Creatinine, mg/dl & $10.2 \pm 3.3$ & $10.0 \pm 3.8$ & $10.5 \pm 3.3$ & $10.3 \pm 3.2$ & $9.5 \pm 3.1$ & 0.06 \\
\hline Calcium, mg/dl & $9.4 \pm 0.7$ & $9.1 \pm 0.7$ & $9.4 \pm 0.7$ & $9.4 \pm 0.7$ & $9.4 \pm 0.7$ & 0.07 \\
\hline Iron, $\mathrm{mg} / \mathrm{dl}$ & $66.6 \pm 26.9$ & $46.6 \pm 18.7$ & $58.6 \pm 21.1$ & $72.4 \pm 26.4$ & $80.4 \pm 33.9$ & $<0.001$ \\
\hline Phosphorus, mg/dl & $5.8 \pm 1.5$ & $6.2 \pm 2.2$ & $5.7 \pm 1.5$ & $5.8 \pm 1.4$ & $5.8 \pm 1.3$ & 0.93 \\
\hline Ferritin, ng/ml & $571 \pm 437$ & $788 \pm 420$ & $638 \pm 392$ & $556 \pm 461$ & $348 \pm 411$ & $<0.001$ \\
\hline Bicarbonate, mg/dl & $22.2 \pm 2.9$ & $22.5 \pm 3.1$ & $22.4 \pm 2.8$ & $22.1 \pm 2.8$ & $22.0 \pm 3.2$ & 0.11 \\
\hline Total homocysteine, $\mu \mathrm{mol} / \mathrm{l}$ & $23.8 \pm 11.0$ & $21.7 \pm 12.2$ & $24.6 \pm 11.7$ & $23.6 \pm 10.7$ & $22.8 \pm 9.5$ & 0.44 \\
\hline C-reactive protein, $\mathrm{mg} / \mathrm{l}$ & $5.7 \pm 6.9$ & $7.9 \pm 5.5$ & $6.2 \pm 8.4$ & $5.5 \pm 5.8$ & $4.2 \pm 4.1$ & 0.001 \\
\hline IL-6, pg/ml & $18.4 \pm 51.5$ & $35.4 \pm 66.4$ & $18.9 \pm 51.2$ & $17.8 \pm 55.8$ & $12.6 \pm 25.5$ & 0.06 \\
\hline TNF- $\alpha, p g / m l$ & $8.9 \pm 12.0$ & $9.2 \pm 11.2$ & $8.4 \pm 10.9$ & $8.6 \pm 10.5$ & $11.0 \pm 17.8$ & 0.18 \\
\hline Blood hemoglobin, g/dl & $12.1 \pm 1.0$ & $11.6 \pm 1.4$ & $11.9 \pm 1.0$ & $12.2 \pm 0.8$ & $12.2 \pm 1.1$ & $<0.001$ \\
\hline WBC, $\times 1,000$ cells $/ \mu \mathrm{l}$ & $7.2 \pm 2.0$ & $7.8 \pm 3.2$ & $7.2 \pm 2.0$ & $7.1 \pm 1.9$ & $7.3 \pm 1.9$ & 0.55 \\
\hline Lymphocytes, \% of total WBC & $22.7 \pm 7.8$ & $21.0 \pm 8.3$ & $22.2 \pm 7.9$ & $23.1 \pm 7.7$ & $23.6 \pm 7.9$ & 0.02 \\
\hline
\end{tabular}

All values are presented as mean $\pm \mathrm{SD}$ or percentages. $\mathrm{Kt} / \mathrm{V}=$ Dialysis dose.

* $\mathrm{p}$ values for dialysis dose (vintage), ferritin, erythropoietin dose, CRP, IL-6, and TNF- $\alpha$ are based on the logarithmic values of these measures.

clinical and laboratory measures the four categories of TIBC. The proportion of women and African-American was higher in the groups with lower TIBC levels; however, there was no trend in terms of having diabetes mellitus and other comorbidities according to the modified Charlson comorbidity score. In addition, the groups of patients with lower serum TIBC had higher dialysis vintage in contrast to their counterparts with higher serum TIBC levels. 
Table 2. Baseline SF- $36^{1}$ health-related quality of life scores across TIBC increments in $624^{2}$ maintenance hemodialysis patients

\begin{tabular}{|c|c|c|c|c|c|}
\hline \multirow[t]{2}{*}{ Variable } & \multicolumn{5}{|c|}{ TIBC, mg/dl } \\
\hline & $\begin{array}{l}<150 \\
(n=28)\end{array}$ & $\begin{array}{l}150 \text { to }<200 \\
(n=254)\end{array}$ & $\begin{array}{l}200 \text { to }<250 \\
(n=252)\end{array}$ & $\begin{array}{l}\geq 250 \\
(n=90)\end{array}$ & $\begin{array}{l}\mathrm{p} \text { for } \\
\text { trend }\end{array}$ \\
\hline \multicolumn{6}{|l|}{ SF-36 overall } \\
\hline SF-36 total score & $48 \pm 21$ & $52 \pm 21$ & $51 \pm 21$ & $49 \pm 21$ & 0.50 \\
\hline \multicolumn{6}{|l|}{ SF-36 dimensions } \\
\hline SF-36 mental health & $51 \pm 22$ & $55 \pm 20$ & $53 \pm 20$ & $53 \pm 20$ & 0.96 \\
\hline SF-36 physical health & $45 \pm 20$ & $48 \pm 23$ & $47 \pm 21$ & $44 \pm 21$ & 0.31 \\
\hline \multicolumn{6}{|l|}{ SF-36 scales } \\
\hline Body pain & $55 \pm 29$ & $60 \pm 28$ & $59 \pm 29$ & $57 \pm 30$ & 0.47 \\
\hline General health & $44 \pm 23$ & $45 \pm 23$ & $46 \pm 21$ & $42 \pm 20$ & 0.81 \\
\hline Mental health & $61 \pm 23$ & $68 \pm 21$ & $66 \pm 19$ & $66 \pm 21$ & 0.82 \\
\hline Physical function & $38 \pm 26$ & $47 \pm 30$ & $47 \pm 30$ & $45 \pm 29$ & 0.99 \\
\hline Role emotional & $42 \pm 45$ & $52 \pm 43$ & $45 \pm 43$ & $47 \pm 42$ & 0.53 \\
\hline Role physical & $38 \pm 40$ & $40 \pm 42$ & $35 \pm 42$ & $26 \pm 36$ & 0.02 \\
\hline Functionality & $60 \pm 28$ & $63 \pm 27$ & $62 \pm 28$ & $62 \pm 28$ & 0.71 \\
\hline Vitality & $49 \pm 24$ & $48 \pm 23$ & $49 \pm 22$ & $48 \pm 22$ & 0.80 \\
\hline
\end{tabular}

Even though MHD patients with lower TIBC levels had lower BMI and triceps and biceps skinfold thicknesses, and, to a lesser extent, had a lower mid-arm muscle circumference, there were no remarkable differences between the four groups of serum TIBC levels with regard to near infrared measured total body fat. Among laboratory measures, serum albumin, transthyretin (pre-albumin), iron, ferritin, and blood hemoglobin levels were lower in the groups with lower TIBC; however, in these same patients, measures of inflammation (i.e. serum CRP and IL-6) were higher.

\section{Health-Related Quality of Life}

Table 2 shows the averaged crude (nonstandardized) scores of SF-36 among $624 \mathrm{MHD}$ patients who answered this HR-QoL questionnaire. The scores are grouped according to the selected serum TIBC increments presented in table 1 . There were no statistically significant associations in most scales and the two dimensions of the SF-36, but there were some trends towards lower HR-QoL scores in the highest and/or lowest TIBC groups.

\section{Linear Associations}

Table 3 shows the correlation coefficients of relevant clinical, nutritional and inflammatory measures with se- rum TIBC levels in 807 MHD patients. Serum TIBC was correlated with the nPNA (nPCR), a surrogate of dietary protein intake as well as serum albumin, transthyretin, ferritin, iron, and logarithms of CRP and IL-6. However, the linear association between serum TIBC and transthyretin no longer persisted after adding serum albumin to the covariates adjusted. Figure 2 demonstrates the positive linear association between serum TIBC and albumin as well as iron, and also, illustrates that when the level of inflammatory markers in serum is increased, the level of serum TIBC decreases.

\section{TIBC and Survival}

Over the 5 years that the cohort was monitored, 241 (30\%) patients died, 95 (12\%) underwent transplantation, and 153 (20\%) left the cohort without further follow-up information. Figure 3 shows the cubic splines graph illustrating the unadjusted and case-mix adjusted associations between baseline serum TIBC and mortality in the 5-year cohort of 807 MHD patients. A somewhat robust trend towards increased risk of death was observed in the MHD patients especially with lower TIBC levels. Figure 4 shows the hazard ratios (HR) of mortality for the four a priori selected groups of serum TIBC levels after stepwise adjustments. The calculated death hazard ratios are shown 
Table 3. Unadjusted and multivariate adjusted Pearson's correlation coefficient of baseline TIBC and other relevant variables in 807 maintenance hemodialysis patients

\begin{tabular}{|c|c|c|c|c|}
\hline Variable & Unadjusted & $\begin{array}{l}\text { Case-mix }{ }^{1} \\
\text { adjusted }\end{array}$ & $\begin{array}{l}\text { Case-mix } \\
+ \text { albumin } \\
\text { adjusted }\end{array}$ & $\begin{array}{l}\text { Case-mix }+ \text { albumin }+ \\
\text { inflammatory markers } \\
(\text { full model })^{2}\end{array}$ \\
\hline \multicolumn{5}{|l|}{ General } \\
\hline Age & $-0.07^{*}$ & $-0.09^{*}$ & -0.02 & -0.01 \\
\hline Charlson comorbidity score & -0.01 & -0.01 & 0.04 & $0.05^{\circ}$ \\
\hline \multicolumn{5}{|l|}{ Nutritional } \\
\hline Body mass index & $0.07^{\circ}$ & $0.10^{* *}$ & $0.10^{* *}$ & $0.14^{* * *}$ \\
\hline Creatinine & $-0.05^{\circ}$ & 0.02 & $-0.05^{\circ}$ & $-0.07^{\circ}$ \\
\hline Triceps skinfold & $0.09^{*}$ & $0.14^{* * *}$ & $0.14^{* * *}$ & $0.16^{* * *}$ \\
\hline Biceps skinfold & $0.08^{*}$ & $0.13^{* *}$ & $0.13^{* * *}$ & $0.16^{* * *}$ \\
\hline Mid-arm muscle circumference & $0.06^{\circ}$ & $0.08^{*}$ & $0.09^{*}$ & $0.10^{*}$ \\
\hline Near infrared measured body fat & 0.09 & $0.11^{* *}$ & $0.11^{* *}$ & $0.14^{* * *}$ \\
\hline Fat weight & $0.05^{*}$ & $0.10^{* *}$ & $0.11^{* *}$ & $0.15^{* * *}$ \\
\hline Lean weight & $0.09^{*}$ & $0.09^{*}$ & $0.11^{* *}$ & $0.14^{* * *}$ \\
\hline $\mathrm{nPCR}$ & $0.11^{* *}$ & $0.08^{*}$ & 0.04 & 0.02 \\
\hline \multicolumn{5}{|l|}{ Laboratory } \\
\hline Albumin & $0.28^{* * *}$ & $0.31^{* * *}$ & - & $0.23^{* * *}$ \\
\hline Prealbumin (transthyretin) & $0.13^{* * *}$ & $0.11^{* *}$ & -0.01 & -0.03 \\
\hline Creatinine & $-0.05^{\circ}$ & 0.02 & $-0.05^{\circ}$ & $-0.07^{\circ}$ \\
\hline Erythropoietin dose & $-0.09^{* *}$ & $-0.08^{*}$ & -0.02 & 0.01 \\
\hline Ferritin & $-0.25^{* * *}$ & $-0.20^{* * *}$ & $-0.21^{* * *}$ & $-0.22^{* * *}$ \\
\hline Iron & $0.35^{* * *}$ & $0.32^{* * *}$ & $0.27^{* * *}$ & $0.25^{* * *}$ \\
\hline Calcium & $0.08^{*}$ & $0.13^{* * *}$ & 0.03 & 0.04 \\
\hline Phosphorus & 0.00 & 0.02 & 0.03 & 0.04 \\
\hline Homocysteine & -0.02 & 0.03 & -0.01 & -0.02 \\
\hline \multicolumn{5}{|l|}{ Inflammatory } \\
\hline $\log$ C-reactive protein & $-0.17^{* * *}$ & $-0.16^{* * *}$ & $-0.12^{* *}$ & $-0.11^{*}$ \\
\hline $\log$ IL-6 & $-0.17^{* * *}$ & $-0.14^{* * *}$ & $-0.06^{\circ}$ & -0.03 \\
\hline $\log$ TNF- $\alpha$ & -0.02 & 0.00 & 0.00 & 0.01 \\
\hline \multicolumn{5}{|c|}{$\begin{array}{l}{ }^{1} \text { Case-mix variables include age, gender, race/ethnicity, diabetes, dialysis vintage, insurance (medicare), } \\
\text { marital status, modified Charlson comorbidity score, dialysis dose }(\mathrm{Kt} / \mathrm{V}) \text {, and kidney residual urine (KRU). } \\
{ }^{2} \text { Full model consist of case-mix variables, albumin, and three inflammatory markers: C-reactive protein, } \\
\text { interleukin- } 6 \text {, tumor necrosis factor- } \alpha \text {. } \\
{ }^{\circ} \text { p value } 0.20 \text { to } 0.05 ;{ }^{*} \text { p value } 0.05 \text { to } 0.01 ;{ }^{* *} \text { p value } 0.01 \text { to } 0.001 ;{ }^{* * *} \text { p value }<0.001 \text {. } \\
\text { Bold = Correlation coefficient }>0.10 \text {. }\end{array}$} \\
\hline
\end{tabular}

in table 4 . A serum TIBC below $150 \mathrm{mg} / \mathrm{dl}$ (5\% of patients) was associated with significantly increased risk of death in the unadjusted and case mix and case mix plus MICS adjusted analyses ( $\mathrm{p}<0.001$ to $\mathrm{p}<0.05$ ), although the $\mathrm{p}$ value increased to 0.24 after full multivariate adjustment that included all nutritional and inflammatory markers including serum albumin, CRP, TNF- $\alpha$ and IL-6.

\section{Changes in TIBC and Survival}

In order to examine whether longitudinal changes in serum TIBC over time affected survival in MHD patients whose serum TIBC was remeasured after 6 months $(\mathrm{n}=$ 625), the magnitude and direction of change in TIBC were calculated. Patients with drop in serum TIBC greater than $20 \mathrm{mg} / \mathrm{dl}$ over the first 6 months of observation had a $57 \%$ increased risk of death compared to those with almost stable TIBC values (table 5). As shown in figure 5, the Kaplan-Meier survival curves for the three groups of changes in serum TIBC levels show a lower survival in patients with a fall in serum TIBC greater than $20 \mathrm{mg} / \mathrm{dl}$ over 6 months. 


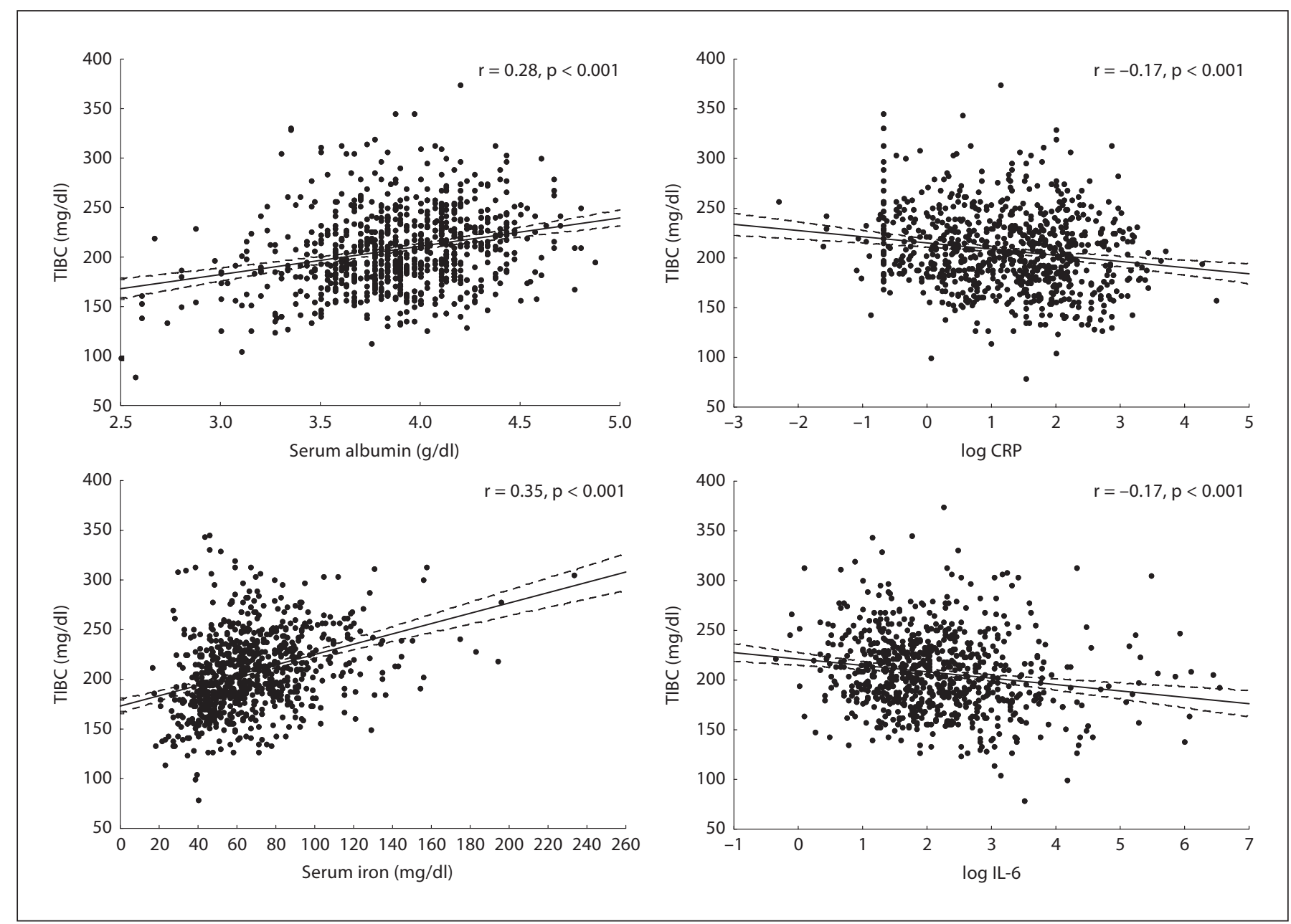

Fig. 2. Scatter plots, regression line and 95\% CIs, reflecting the correlation between TIBC and baseline serum albumin, serum iron, log for CRP, and log for IL-6.

\section{Discussion}

We found that serum TIBC, an indirect measurement of serum transferrin concentration, is correlated with several markers of nutrition and inflammation in 807 MHD patients who participated in a prospective 5-year study in Southern California. Patients with lower TIBC levels, i.e. $<150 \mathrm{mg} / \mathrm{dl}$, had lower BMI, triceps and biceps skin folds and mid-arm muscle circumference compared to those with higher serum TIBC. A trend of low self-reported HR-QoL and poor survival was observed with the lowest and/or highest serum TIBC concentrations even after exhaustive multivariate adjustment for other surrogates of malnutrition and inflammation. A fall in serum TIBC beyond $20 \mathrm{mg} / \mathrm{dl}$ over 6 months was associated with $57 \%$ increased risk of death in the subsequent years.
These findings may indicate that serum TIBC is a useful and robust marker of nutritional status with clinically relevant associations with inflammatory markers, iron stores and survival and that its longitudinal changes over time can modify the risk of death in MHD patients.

Individuals with CKD have an exceptionally high mortality rate and a high burden of cardiovascular disease [26]. About one of every 5 of the 400,000 MHD patients in the United States die every year [28]. Even though half of all these deaths are attributed to cardiovascular disease [28], measures of PEW, and not traditional mortality risk factors, are the strongest predictors of mortality in MHD patients [2]. Therefore, reliable markers of PEW with stronger and more robust associations with morbidity and mortality in MHD patients are needed, so that patients at risk can better be identi- 


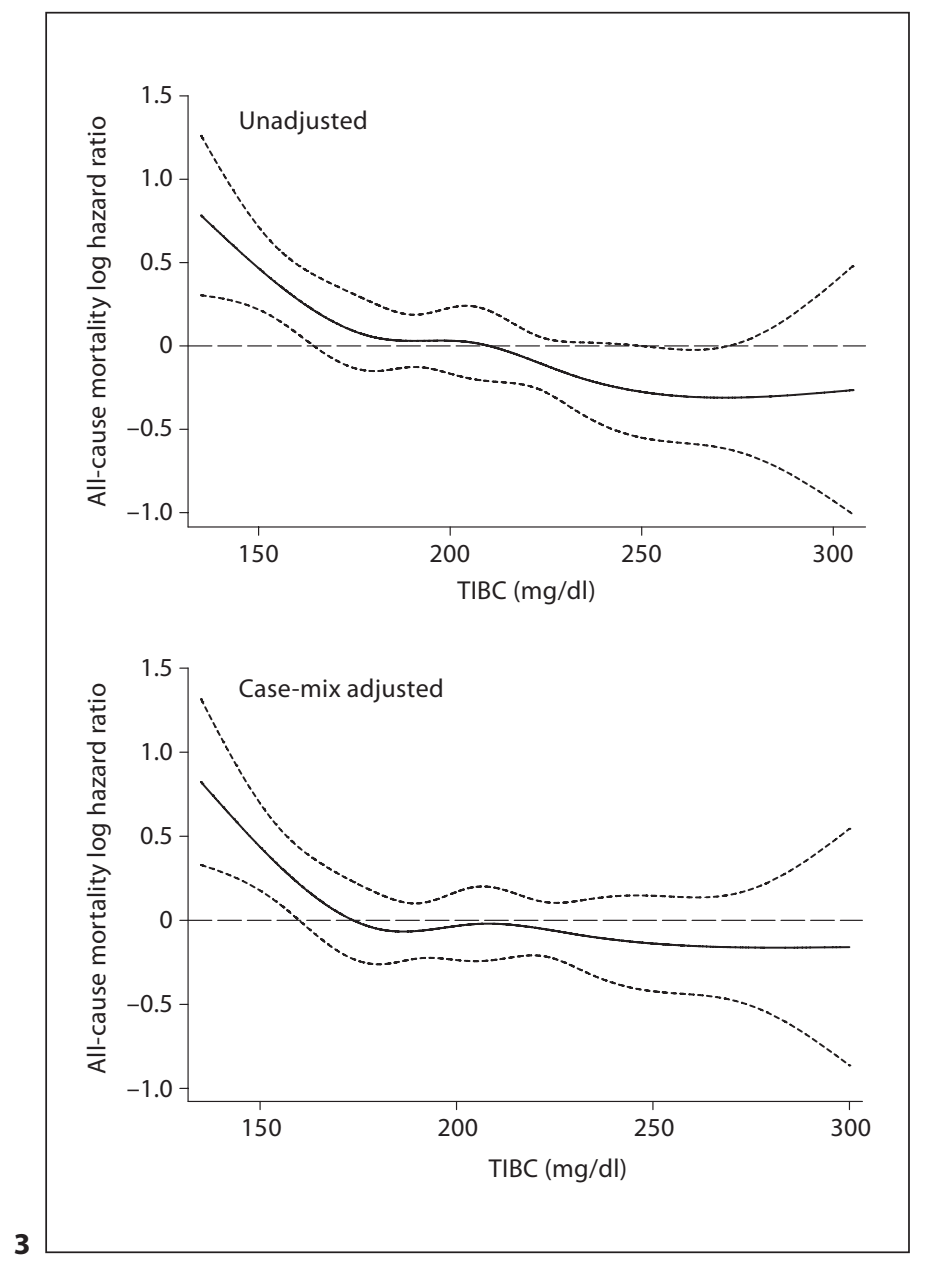

fied for focused nutritional and anti-inflammatory interventions.

We found that serum TIBC had the strongest positive correlation with serum iron and negative correlation with serum ferritin concentrations (table 3; fig. 2). The positive association of serum TIBC with iron in our current study, as well as in previous studies [7], appears to be in sharp contradistinction to its known reverse association with iron in the general population. Indeed, in the non-CKD populations, iron deficiency is associated with concurrent decreased serum iron and increased TIBC levels, so that iron divided by TIBC, also known as iron saturation ratio, is usually quite low [12]. In dialysis patients, on the contrary, TIBC could be low in the setting of malnutrition, inflammation or iron deficiency. Hence, use of traditionally calculated iron saturation ratio, i.e., iron divided by TIBC, to rule out iron deficiency may be misleading, since this simple algebraic fraction may erroneously be normal to high in the setting of MICS or

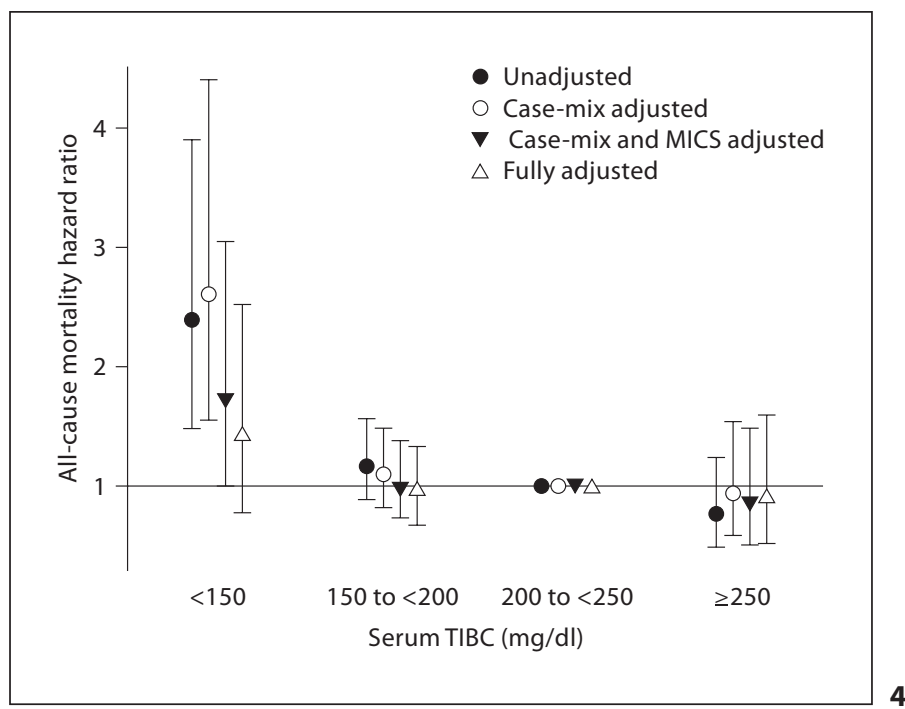

Fig. 3. Unadjusted (upper panel) and case-mix adjusted (lower panel) spline models with $95 \%$ CI reflecting mortality predictability of serum TIBC in 807 maintenance hemodialysis patients (Oct. 2001 to Jan. 2007).

Fig. 4. Mortality predictability of serum TIBC in 807 maintenance hemodialysis patients (Oct. 2001 to Jan. 2007). Case-mix variables: age, gender, race/ethnicity, diabetes mellitus, dialysis vintage, primary insurance, marital status, Charlson co-morbidity score, dialysis dose (Kt/V), kidney residual urine (KRU), and serum iron. MICS variables: albumin, erythropoietin dose, creatinine, hemoglobin, phosphorus, normalized protein catabolic rate (nPCR), bicarbonate, calcium, ferritin, WBC, lymphocyte percentage, body mass index, and vitamin $\mathrm{D}$ dose. Inflammatory variables: CRP, IL-6, TNF- $\alpha$.

even true iron deficiency. Furthermore, the negative association of TIBC with ferritin, a positive acute-phase reactant, underscores the hypothesis that TIBC is a negative acute-phase reactant.

In our study, the associations between baseline serum TIBC and death were attenuated after multivariate adjustment, especially after exhaustive adjustment for a number of markers of iron stores, nutrition and inflammation. This may be due to the collinearity between serum transferrin, as a nutritional marker and possibly a negative acute-phase reactant per se, and other markers of MICS. However, the fall in transferrin over time remained a robust predictor of worsening risk of death even after exhaustive multivariate adjustment for serum albumin, CRP, IL-6 and other covariates. Our study also examined the mortality predictability of longitudinal changes in serum TIBC over time. Patients whose serum TIBC decreased after 6 months subsequently had a 57\% higher risk of death compared to those with stable serum 
Table 4. Hazard ratios (HRs) of 5-year mortality according to the four a priori selected groups of TIBC in 807 maintenance hemodialysis patients (Oct. 2001 to Jan. 2007)

\begin{tabular}{|c|c|c|c|c|c|c|c|c|c|c|}
\hline \multirow[t]{3}{*}{ TIBC group } & \multicolumn{10}{|c|}{ Proportional hazard model } \\
\hline & \multicolumn{2}{|l|}{ unadjusted } & \multicolumn{2}{|c|}{ case-mix ${ }^{1}$ adjusted } & \multicolumn{2}{|c|}{$\begin{array}{l}\text { case-mix + albumin } \\
\text { adjusted }\end{array}$} & \multicolumn{2}{|c|}{$\begin{array}{l}\text { case-mix + } \text { MICS }^{2} \\
\text { adjusted }\end{array}$} & \multicolumn{2}{|c|}{$\begin{array}{l}\text { case-mix }+ \text { MICS }+ \\
\text { inflammation adjusted } \\
(\text { full model })^{3}\end{array}$} \\
\hline & HR (95\% CI) & $\mathrm{p}$ & HR (95\% CI) & $\mathrm{p}$ & HR (95\% CI) & $\mathrm{p}$ & HR (95\% CI) & $\mathrm{p}$ & HR (95\% CI) & $\mathrm{p}$ \\
\hline$<150 \mathrm{mg} / \mathrm{dl}$ & $2.4(1.5-3.9)$ & $<0.001$ & $2.6(1.6-4.4)$ & $<0.001$ & $1.8(1.1-3.1)$ & 0.03 & $1.8(1.0-3.1)$ & 0.05 & $1.4(0.8-2.5)$ & 0.24 \\
\hline 150 to $<200 \mathrm{mg} / \mathrm{dl}$ & $1.2(0.9-1.6)$ & 0.24 & $1.1(0.8-1.5)$ & 0.50 & $1.0(0.7-1.4)$ & 0.99 & $1.0(0.7-1.4)$ & 0.97 & $1.0(0.7-1.3)$ & 0.78 \\
\hline 200 to $<250 \mathrm{mg} / \mathrm{dl}$ & 1.0 (reference) & & 1.0 (reference) & & 1.0 (reference) & & 1.0 (reference) & & 1.0 (reference) & \\
\hline$\geq 250 \mathrm{mg} / \mathrm{dl}$ & $0.8(0.5-1.2)$ & 0.29 & $0.9(0.6-1.5)$ & 0.85 & $0.9(0.6-1.5)$ & 0.81 & $0.9(0.5-1.5)$ & 0.62 & $0.9(0.5-1.6)$ & 0.76 \\
\hline
\end{tabular}

\footnotetext{
${ }^{1}$ Case-mix variables include age, gender, race/ethnicity, diabetes, dialysis vintage, insurance (medicare), marital status, Charlson comorbidity score, dialysis dose $(\log \mathrm{Kt} / \mathrm{V})$, kidney residual urine (KRU), and serum iron.

${ }_{2}^{2}$ MICS variables include albumin, log erythropoietin dose, creatinine, hemoglobin, phosphorus, normalized protein catabolic rate (nPCR), bicarbonate, calcium, $\log$ ferritin, WBC, lymphocyte percent, body mass index, log vitamin D dose.

${ }^{3}$ Full model consists of case-mix variables, MICS, and three inflammatory markers: CRP, IL- 6 , and TNF- $\alpha$.
}

Table 5. Hazard ratios (HRs) of 5-year mortality according to the three a priori selected groups of change in TIBC in 625 maintenance hemodialysis patients (Oct. 2001 to Jan. 2007)

\begin{tabular}{|c|c|c|c|c|c|c|c|c|c|c|}
\hline \multirow[t]{2}{*}{ Change in TIBC } & \multicolumn{2}{|c|}{$\begin{array}{l}\text { Adjusted for baseline } \\
\text { serum TIBC }\end{array}$} & \multicolumn{2}{|c|}{$\begin{array}{l}\text { Baseline serum TIBC } \\
+ \text { case-mix }^{1} \text { adjusted }\end{array}$} & \multicolumn{2}{|c|}{$\begin{array}{l}\text { Baseline serum TIBC } \\
+ \text { case-mix }+ \\
\text { albumin adjusted }\end{array}$} & \multicolumn{2}{|c|}{$\begin{array}{l}\text { Baseline serum TIBC } \\
+ \text { case-mix + } \text { MICS }^{2} \\
\text { adjusted }\end{array}$} & \multicolumn{2}{|c|}{$\begin{array}{l}\text { Baseline serum TIBC } \\
+ \text { case-mix + MICS } \\
+ \text { inflammation ad- } \\
\text { justed (full model) }\end{array}$} \\
\hline & HR (95\% CI) & $\mathrm{p}$ & HR (95\% CI) & $\mathrm{p}$ & HR $(95 \%$ CI $)$ & $\mathrm{p}$ & HR (95\% CI) & $\mathrm{p}$ & HR (95\% CI) & $\mathrm{p}$ \\
\hline$<-20 \mathrm{mg} / \mathrm{dl}(\mathrm{n}=151)$ & $1.6(1.1-2.3)$ & 0.01 & $1.4(0.95-2.0)$ & 0.09 & $1.4(1.0-2.0)$ & 0.07 & $1.5(1.0-2.3)$ & 0.03 & $1.6(1.1-2.4)$ & 0.02 \\
\hline-20 to $<+20 \mathrm{mg} / \mathrm{dl}(\mathrm{n}=368)$ & 1.0 (reference) & & 1.0 (reference) & & 1.0 (reference) & & 1.0 (reference) & & 1.0 (reference) & \\
\hline$\geq+20 \mathrm{mg} / \mathrm{dl}(\mathrm{n}=106)$ & $0.9(0.6-1.4)$ & 0.84 & $1.0(0.7-1.5)$ & 0.99 & $0.9(0.6-1.4)$ & 0.73 & $1.0(0.6-1.6)$ & 0.98 & $0.9(0.6-1.4)$ & 0.64 \\
\hline
\end{tabular}

${ }^{1}$ Case-mix variables include age, gender, race/ethnicity, diabetes, dialysis vintage, insurance (medicare), marital status, Charlson comorbidity score, dialysis dose $(\log \mathrm{Kt} / \mathrm{V})$, kidney residual urine (KRU), and serum iron.

${ }_{2}^{2}$ MICS variables include albumin, log erythropoietin dose, creatinine, hemoglobin, phosphorus, normalized protein catabolic rate (nPCR), bicarbonate, calcium, log ferritin, white blood count (WBC), lymphocyte percent, body mass index, log vitamin D dose.

${ }^{3}$ Full model consists of case-mix variables, MICS, and three inflammatory markers: CRP, IL-6, and TNF- $\alpha$.

TIBC (table 5; fig. 5). Although the opposite association, i.e. between a rise in TIBC and improved survival, was not evident except for a lower mortality rate observed in the Kaplan-Meier graphs (fig. 5). These general findings may imply that monitoring changes in serum TIBC can help identify patients at risk, who may benefit from nutritional interventions, especially if the TIBC fall is greater than $20 \mathrm{mg} / \mathrm{dl}$ over 6 months. To our knowledge, this is the first study that has examined outcome predictability of both baseline TIBC and its changes over time and the confounding effect of other measures of inflammation and wasting on these associations.
A potential limitation of the present study is a selection bias during enrollment [13]. However, since the mortality in our cohort was less than the base population, it might be argued that a selection bias with such a direction generally would lead to a bias toward the null hypothesis, so without this bias, our positive results may have been even stronger. The strengths of our study include the sample size, which was moderately large, the comprehensive clinical and laboratory evaluations with repeated measures of serum TIBC, concomitant assessment of HR-QoL and body composition measures, and detailed evaluation of comorbid states by study physicians at baseline. Unlike previous cohorts that have been 


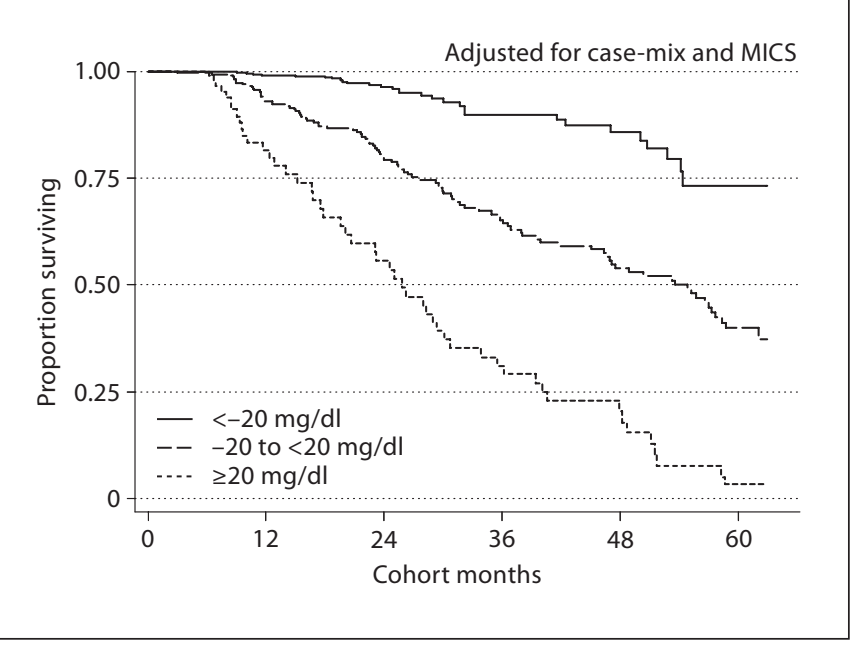

Fig. 5. Kaplan-Meier proportion of surviving MHD patients after 5 years of observation according to the three a priori selected groups of changes in TIBC during the first 6 months of observation in 625 MHD patients (adjusted for case-mix and MICS variables). Case-mix variables: age, gender, race/ethnicity, diabetes mellitus, dialysis vintage, primary insurance, marital status, Charlson co-morbidity score, dialysis dose (Kt/V), and kidney residual urine (KRU), and serum iron. MICS variables: albumin, erythropoietin dose, creatinine, hemoglobin, phosphorus, normalized protein catabolic rate (nPCR), bicarbonate, calcium, ferritin, WBC, lymphocyte percentage, body mass index, and vitamin D dose.

studied, ours has been extensively characterized for markers of inflammation and nutritional status, including direct total body fat measurements. The availability of these measures allowed us to demonstrate that the serum transferrin concentration was strongly associated with mortality risk independent of influences from other known inflammatory markers or comorbid states in this group of MHD patients. Another strength of this cohort is that the subjects were selected randomly without having any prior knowledge of their inflammation status. Finally, the very same blood specimens that were utilized to measure markers of PEW and cytokines were also used for the TIBC measurements.

In conclusion, we found that serum transferrin, as measured by TIBC, correlated with several surrogates of body composition and several components of HR-QoL in MHD patients and that a low baseline serum transferrin (i.e. $<150 \mathrm{mg} / \mathrm{dl}$ ) and especially its decline over time was independently associated with a trend towards increased risk of death. These data may also justify the inclusion of serum TIBC or transferrin as one of the 10 components of the 'Malnutrition-Inflammation Score' [4]. Understanding the role of TIBC or transferrin in the MHD population may lead to more useful strategies to identify patients at risk of PEW and to the development of focused nutritional interventions to improve nutritional status and, hence, survival in almost half a million dialysis patients and over the 20 million individuals with CKD in the United States and many more throughout the world.

\section{Acknowledgements}

The abstract of this manuscript was presented during the annual meeting of the National Kidney Foundation, April 4-8, 2008, Dallas, Tex., USA. The authors are thankful to Ms. Stephanie Griffith at Harbor-UCLA GCRC Core Laboratories for the management of blood samples and measuring inflammatory markers, and Dr. John Steinmetz, Senior Manager of Laboratory Operations, DaVita Laboratory Services, Deland, Fla., for providing the details of measurement techniques for TIBC.

Funding Sources

This study was supported by an investigator initiated research grant from Watson pharmaceuticals, a National Institutes of Health, National Institute of Diabetes, Digestive and Kidney Disease grant \# K23-DK61162, a research grant from DaVita Clinical Research, a philanthropist grant from Mr. Harold Simmons (all for K.K.-Z.), and a General Clinical Research Center grant \# M01RR00425 from the National Centers for Research Resources, National Institutes of Health.

\section{Potential Conflict of Interests}

K.K.-Z has received grants and/or honoraria from Watson (manufacturer of Ferrlecit ${ }^{\mathrm{TM}}$ ), and NovoNordisk (manufacturer of Nortropin ${ }^{\mathrm{TM}}$ ). J.D.K. has received grants and honoraria from NovoNordisk. Other authors have declared no conflict of interest.

References

1 Clinical practice guidelines for nutrition in chronic renal failure. K/DOQI, National Kidney Foundation. Am J Kidney Dis 2000; 35:S1-S140.

2 Fouque D, Kalantar-Zadeh K, Kopple J, et al: A proposed nomenclature and diagnostic criteria for protein-energy wasting in acute and chronic kidney disease. Kidney Int 2008; 73:391-398.

3 Pupim LB, Caglar K, Hakim RM, et al: Uremic malnutrition is a predictor of death independent of inflammatory status. Kidney Int 2004;66:2054-2060.

4 Kalantar-Zadeh K, Kopple JD, Block G, et al: A malnutrition-inflammation score is correlated with morbidity and mortality in maintenance hemodialysis patients. Am J Kidney Dis 2001;38:1251-1263. 
$\checkmark 5$ Kopple JD: Effect of nutrition on morbidity and mortality in maintenance dialysis patients. Am J Kidney Dis 1994;24:1002-1009.

-6 Kalantar-Zadeh K, Kopple JD, Block G, et al: Association among SF36 quality of life measures and nutrition, hospitalization, and mortality in hemodialysis. J Am Soc Nephrol 2001;12:2797-2806.

7 Kalantar-Zadeh K, Kleiner M, Dunne E, et al: Total iron-binding capacity-estimated transferrin correlates with the nutritional subjective global assessment in hemodialysis patients. Am J Kidney Dis 1998;31:263-272.

$\checkmark 8$ Marckmann P: Nutritional status of patients on hemodialysis and peritoneal dialysis. Clin Nephrol 1988;29:75-78.

$\checkmark 9$ Ooi BS, Darocy AF, Pollak VE: Serum transferrin levels in chronic renal failure. Nephron 1972;9:200-207.

-10 Miura Y: Serum transferrin levels in chronic renal failure. II. The relationship between anemia and nutrition in regular hemodialysis patients (author's translation). Nippon Jinzo Gakkai Shi 1978;20:243-253.

$\checkmark 11$ Kalantar-Zadeh K, Hoffken B, Wunsch H, et al: Diagnosis of iron deficiency anemia in renal failure patients during the post-erythropoietin era. Am J Kidney Dis 1995;26:292299.

-12 Kalantar-Zadeh K, Kalantar-Zadeh K, Lee $\mathrm{GH}$ : The fascinating but deceptive ferritin: to measure it or not to measure it in chronic kidney disease? Clin J Am Soc Nephrol 2006; 1(suppl 1):S9-S18.
13 Colman S, Bross R, Benner D, et al: The Nutritional and Inflammatory Evaluation in Dialysis patients (NIED) study: overview of the NIED study and the role of dietitians. J Ren Nutr 2005;15:231-243.

14 Mehrotra R, Kermah D, Fried L, et al: Chronic peritoneal dialysis in the United States: declining utilization despite improving outcomes. J Am Soc Nephrol 2007; 18:27812788.

15 Beddhu S, Bruns FJ, Saul M, et al: A simple comorbidity scale predicts clinical outcomes and costs in dialysis patients. Am J Med 2000;108:609-613.

16 Diaz-Buxo JA, Lowrie EG, Lew NL, et al: Quality-of-life evaluation using Short Form 36: comparison in hemodialysis and peritoneal dialysis patients. Am J Kidney Dis 2000; 35:293-300.

17 Nelson EE, Hong CD, Pesce AL, et al: Anthropometric norms for the dialysis population. Am J Kidney Dis 1990;16:32-37.

18 Williams AJ, McArley A: Body composition, treatment time, and outcome in hemodialysis patients. J Ren Nutr 1999;9:157-162.

19 Kalantar-Zadeh K, Dunne E, Nixon K, et al: Near infra-red interactance for nutritional assessment of dialysis patients. Nephrol Dial Transplant 1999;14:169-175.

20 Kalantar-Zadeh K, Kuwae N, Wu DY, et al: Associations of body fat and its changes over time with quality of life and prospective mortality in hemodialysis patients. Am J Clin Nutr 2006;83:202-210.
21 Reinecke V, Naegele W, Strotges MW, et al: In vitro determination of unbound and total iron-binding capacity in serum by radioiron using a new ion exchange strip. Nuklearmedizin 1976;15:119-125.

22 Ridker PM, Rifai N, Rose L, et al: Comparison of C-reactive protein and low-density lipoprotein cholesterol levels in the prediction of first cardiovascular events. N Engl J Med 2002;347:1557-1565.

23 Erbagci AB, Tarakcioglu M, Aksoy M, et al: Diagnostic value of CRP and Lp(a) in coronary heart disease. Acta Cardiol 2002;57: 197-204.

24 Pecoits-Filho R, Barany P, Lindholm B, et al: Interleukin- 6 is an independent predictor of mortality in patients starting dialysis treatment. Nephrol Dial Transplant 2002;17: 1684-1688.

25 Beutler B, Cerami A: The biology of cachectin/TNF: a primary mediator of host response. Ann Rev Immunol 1989;7:625-655.

26 Go AS, Chertow GM, Fan D, et al: Chronic kidney disease and the risks of death, cardiovascular events, and hospitalization. N Engl J Med 2004;351:1296-1305.

27 Durrleman S, Simon R: Flexible regression models with cubic splines. Stat Med 1989;8: 551-561.

28 United States Renal Data System: Excerpts from the USRDS 2005 Annual Data Report: Atlas of End-Stage Renal Disease in the United States, National Institutes of Health, National Institute of Diabetes and Digestive and Kidney Diseases. Am J Kid Dis 2006; 47(suppl 1):1-286. 